\title{
ASO Visual Abstract: A National Survey of Breast Surgeons and Radiation Oncologists on Contemporary Axillary Management in Mastectomy Patients
}

\section{Chandler S. Cortina, $\mathrm{MD}^{1}$ (D), Carmen Bergom, $\mathrm{MD}, \mathrm{PhD}^{2,3}$, Morgan Ashley Craft, $\mathrm{BS}^{\mathbf{1}}$,} British Fields, (MLS)ASCP${ }^{1}$, Ruta Brazauskas, $\mathrm{PhD}^{4}$, Adam Currey, $\mathrm{MD}^{3}$, and Amanda L. Kong, MD, MS

${ }^{1}$ Section of Breast Surgery, Division of Surgical Oncology, Department of Surgery, Medical College of Wisconsin, Milwaukee, WI; ${ }^{2}$ Department of Radiation Oncology and Siteman Cancer Center, Washington University School of Medicine, St Louis, MO; ${ }^{3}$ Department of Radiation Oncology, Medical College of Wisconsin, Milwaukee, WI; ${ }^{4}$ Division of Biostatistics, Institute of Health and Equity, Medical College of Wisconsin, Milwaukee, WI

A national case-based survey of breast surgeons and radiation oncologists found significant heterogeneity in the treatment of breast cancer patients who were clinically node-negative, underwent upfront mastectomy, and were found to have pathological nodal involvement on sentinel lymph node biopsy (https://doi.org/10.1245/s10434-021-1 0441-z).

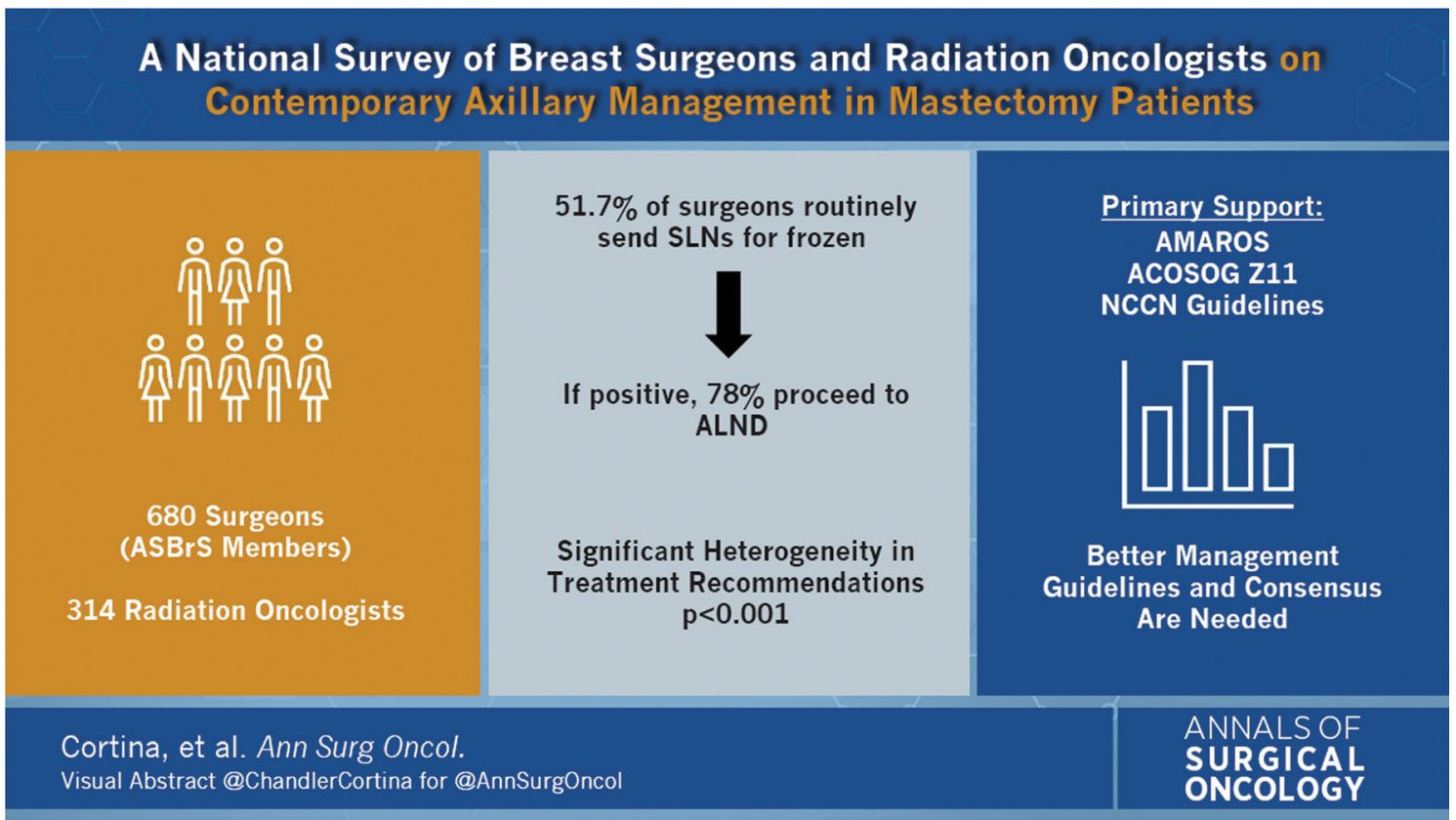

(C) Society of Surgical Oncology 2021

DISCLOSURES Chandler S. Cortina, Carmen Bergom, Morgan Ashley Craft, British Fields, Ruta Brazauskas, Adam Currey, and Amanda L. Kong have no relevant disclosures to report.

Published Online: 9 August 2021

C. S. Cortina, MD

Publisher's Note Springer Nature remains neutral with regard to e-mail: ccortina@mcw.edu jurisdictional claims in published maps and institutional affiliations. 